\title{
MORPHOLOGICAL COMPARISON OF THREE ASIAN NATIVE HONEY BEES (APIS CERANA, A. DORSATA, A. FLOREA) IN NORTHERN VIETNAM AND THAILAND
}

\author{
N.V. NIEM and L. Q. TRUNG \\ Vietnam Bee Research and Development Center \\ Long ha, Dongda, Hanoi, Vietnam
}

\begin{abstract}
Three species of Asian native honey bees (Apis cerana, A. florea and A. dorsata) from northern Vietnam and Thailand were morphologically analyzed for investigations on their geographic variations and relations. In Vietnam, samples were collected from feral and managed colonies. In Thailand, the collections were from feral colonies or from field bees on flowers. Morphological analysis was carried out, using measurements common to honeybee taxonomy. Measured characters were done under stereomicroscope with an ocular micrometer. ANOVA program and multivariate statistical analyses were applied for treating the data. Overall, A. cerana populations in northern Vietnam are significantly morphologically different than from those in Thailand. It may be due to their different geographic locations between the Thai and Vietnamese populations of A. cerana. A. florea bees from Vietnam are generally bigger in size than those from Thailand, but the differences are uncertain. In contrast, the body size of A. dorsata populations from Thailand are bigger than those from Vietnam. However, these differences are also not significant. It is necessary to take further comparative investigations of these bee species from both countries.
\end{abstract}

Key words: Honey bee/Apis cerana/Apis dorsata/ApisJlorea/moif> hology

\section{INTRODUCTION}

In the genus Apis, eastern honey bees (Apis cerana), giant honey bees (Apis dorsata), and dwarf honey bees (Apis florea and Apis andreniformis) are native to many countries in Southeast Asia. These bee species play an important role in producing large amount of valuable products for people and in pollinating agricultural crops. However, their value is not well documented. The studies of their biological and economic characteristics being useful for strains improvement are less than those of European honey bees (A. mellifera).

A few publications relate to geographical variations and distribution of these honey bee species in different parts of Southeast Asia. Ruttner (1988) reviewed the geographical distribution of A. dorsata, A cerana, A. florea in Asia. Verma (1990) made an extensive investigation on the distributions of $A$. cerana in India. Peng et al. (1989) reviewed studies on the biology and distribution of races of $A$. cerana in China. A morphological analysis of A. cerana and A. nigrocincta populations from Southeast Asia has been taken by Damus and Otis (1997). Rinderer et al. (1995) published data on comparative morphology of the dwarf honey bees in Southeast Thailand and Palawan, Philippines. Wongsiri et al. (1993) carried out a comparative investigation of some biological characteristics of $A$. cerana bees in China, Thailand and their hybrids for the purpose of using biological measures to control Varroa parasitic mites. 
Therefore, at present, there is a big gap in information on the genetic biodiversity of Asian native honey bees. It is not clear how many subspecies and ecotypes of these native bee species exist in Southeast Asia and how they are related to each other.

The purpose of this paper is to present some preliminary results on comparative morphology of the three honey bee species: A. cerana, A. florea and A. dorsata in Vietnam and Thailand to contribute basic information on certain morphological parameters.

\section{MATERIALS AND METHODS}

In Vietnam, samples of the three honey bee species were collected from locations of four provinces in the North (Haiphong, Laichau, Hoabinh, Nghean). At each location, four to six colonies were sampled. From each single colony, a sample of 40 '-60 worker bees was collected.

In Thailand, A. cerana samples were collected in Bangkok, partly from a feral colony, partly from field bees on flowers in the gardens. A. florea bees were also collected on flowers. A. dorsata bees were sampled in Nan Province by using high voltage light trap to attract the bees from 14 colonies in one tree to the light. This sample should contain bee individuals from different colonies.

The sampled bees were killed with hot water (around $90^{\circ} \mathrm{C}$ ) to obtain their stretched proboscis, then they were preserved in $70 \%$ ethanol. Thirty worker bees of each location (five to ten bees per sample) were selected and analyzed morphologically on temporary slide preparations. The following morphological measurements were recorded:
1. Length of proboscis
8. Length of basitarsus
2. Width of prementum
9. Width of basitarsus
3. Length of forewing
10. Tergite 3, longitudinal
4. Width of forewing
11. Tergite 3 , transverse
5. Cubital index
12. Stemite 3 , longitudinal
6. Length of femur
13. Stemite 3, transverse
7. Length of tibia
14. Wax plate of sternite 3 , longitudinal
15. Wax plate of stemite 3 , transverse

The measurement was done according to the Ruttner's methods (1988), using a stereomicroscope with an ocular micrometer. For most parts, numbers presenting lengths or widths of various structures are in millimeters.

The data were analyzed using ANOVA program, and the Student's $t$ test was used to test the null hypothesis from the two equal sources of data. A clustering analysis was also applied to analyze the relationship between two honey bee populations, and establish their tree diagrams. 


\section{RESULTS}

The results of morphometric measurements from these honey bee species are presented in Table 1. The results show that the body size of A. cerana in Vietnam was bigger than that in Thailand. Of the 15 measured characters, the values of 11 characters were significantly bigger $(1,3,4,5,6,8,9,10,11,12,13,14)$ particularly the cubital index, while the width of prementum and forewing were smaller.

The body size of $A$. florea in Vietnam was also bigger than those from Thailand. However, these differences were not clear. Six characters $(3,4,5,6,12$, 14) of the bees from Vietnam were significantly larger than those from Thailand. The remaining characters were slightly larger $(10,13)$, equal $(2,7,9,15)$ or smaller $(1$, $8,11)$. In contrary to $A$. cerana and $A$. florea, the body size of $A$. dorsata in Thailand was bigger than those from Vietnam. Qf 15 measured characters, the value of 11 characters of $A$. dorsata in Thailand were higher $(2,3,4,5,6,7,8,11,12,14$, $15)$, one character was equal (10) and three characters were smaller $(1,9,13)$. Interestingly, while the cubital index of A. cerana and A. florea in Thailand were significantly bigger than those in Vietnam, this character in A. dorsata of both countries was not significantly different.

\section{DISCUSSIONS}

The differences in body parts between A. cerana populations from Vietnam and Thailand are reasonably significant. Twelve larger measured characters of $A$. cerana in Vietnam indicate that these two honey bee populations may be considered as separating geographical groups. According to Ruttner( 1988), the characters that can be considered to distinguish bee populations into subspecies levels are lengths of basitarsus, tergite 4 , sternite 3 , wax plate transverse of sternite 3 , and cubital index. In this study, all these characters are significantly different between the two populations. The tree linkage diagram analysis (Figure 1-a) shows the bee population in Vietnam is also clearly distinguished from that in Thailand. All the Vietnamese bee populations are ranged in a distinct group (from 1 to 15) separated from the Thai group ( from 16 to 30 ) and there is no overlap between them.

Our data support the Ruttner's (1988) statement that $A$. cerana can be distinguished into two subspecies: A. cerana cerana and A. cerana indica. The former includes the bees of Vietnam, Afghanistan, Pakistan, North India and China. The later includes the bees of Thailand, Malaysia, Myanmar, Bangladesh, Sri Lanka and South India, Indonesia, Philippines. Comparing these results to the data of Peng et $\mathrm{a} / .(1989)$ and Verma (1990), it is recognized that the A. cerana bees from Vietnam are closer to the bees in Southern Yunnan (China) and Nepal, while A. cerana bees from Thailand are closer to the bees in Southern India. 
BIOTROPIA No. 14, 1999

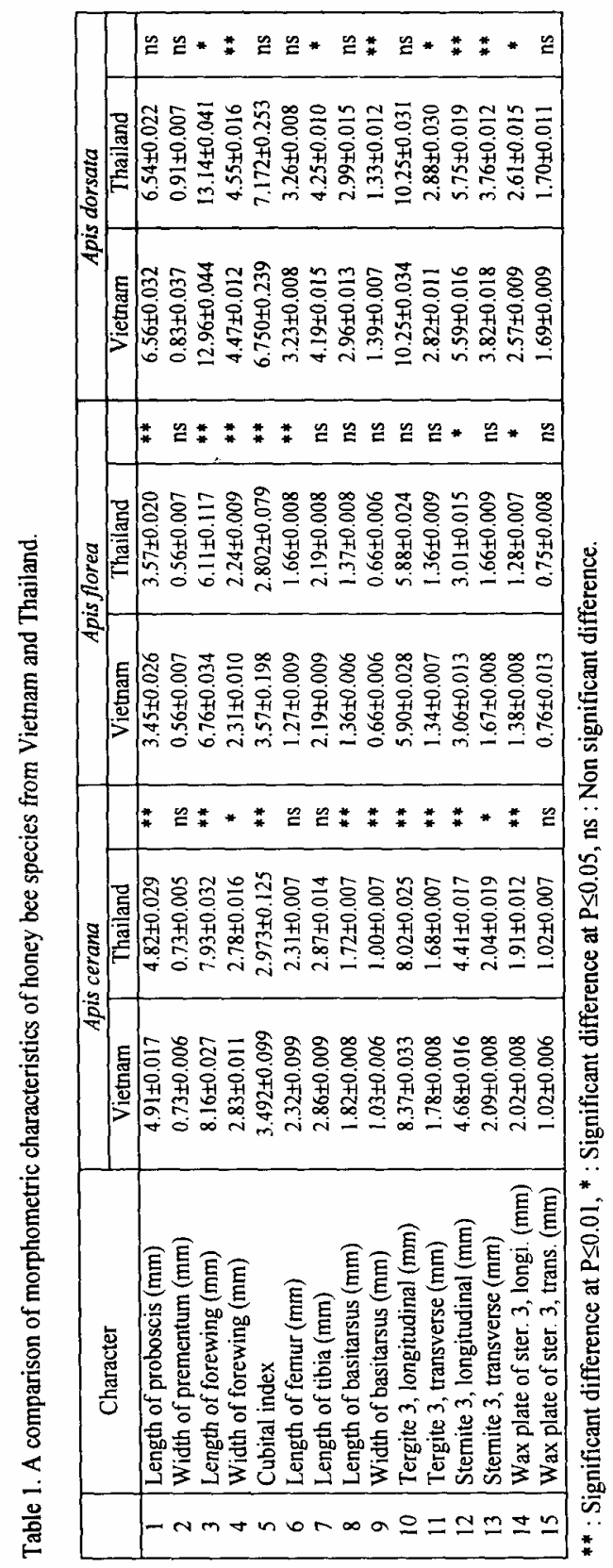


Morphological comparison of three Asian native honey bees - N.V. Niem \& L.Q. Trung

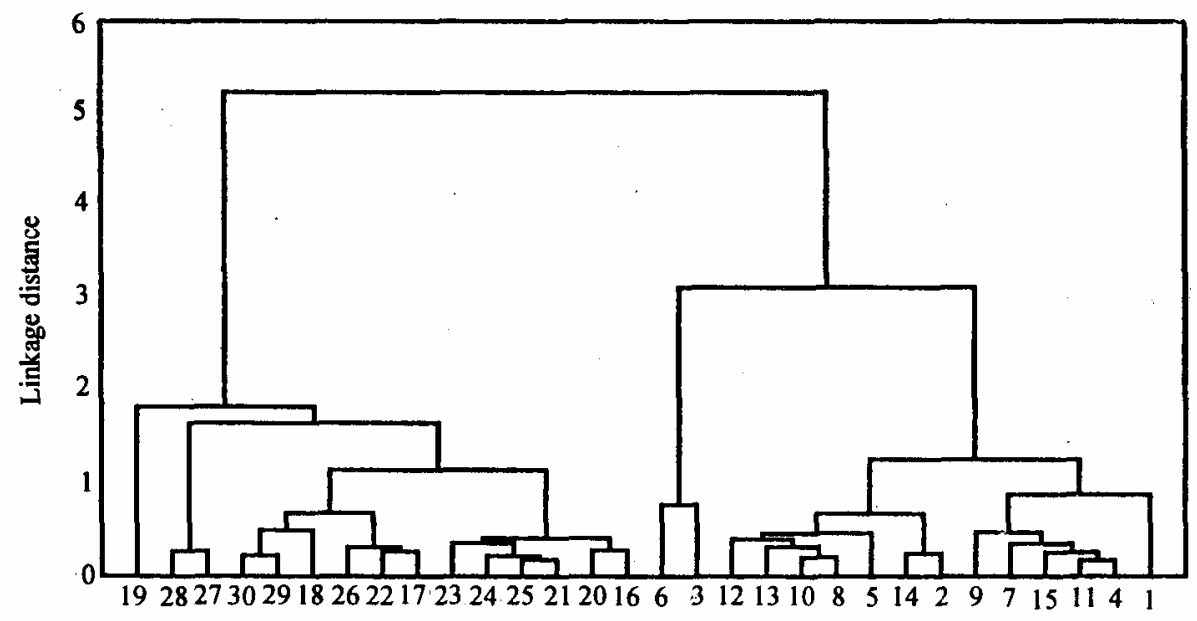

Figure la Tree linkage diagram of Apis cerana bee populations from Northern Vietnam (1-15) and Thailand (16-30).

Overall, the body size of A. florea from Vietnam is slightly bigger than those from Thailand. However, the differences between these bee populations are too small to consider them as different ecotypes. The tree diagram (Figure 1-b) shows an overlap between these two populations. Therefore, it is necessary to take further studies on the relationship of these bee populations between Vietnam and Thailand.

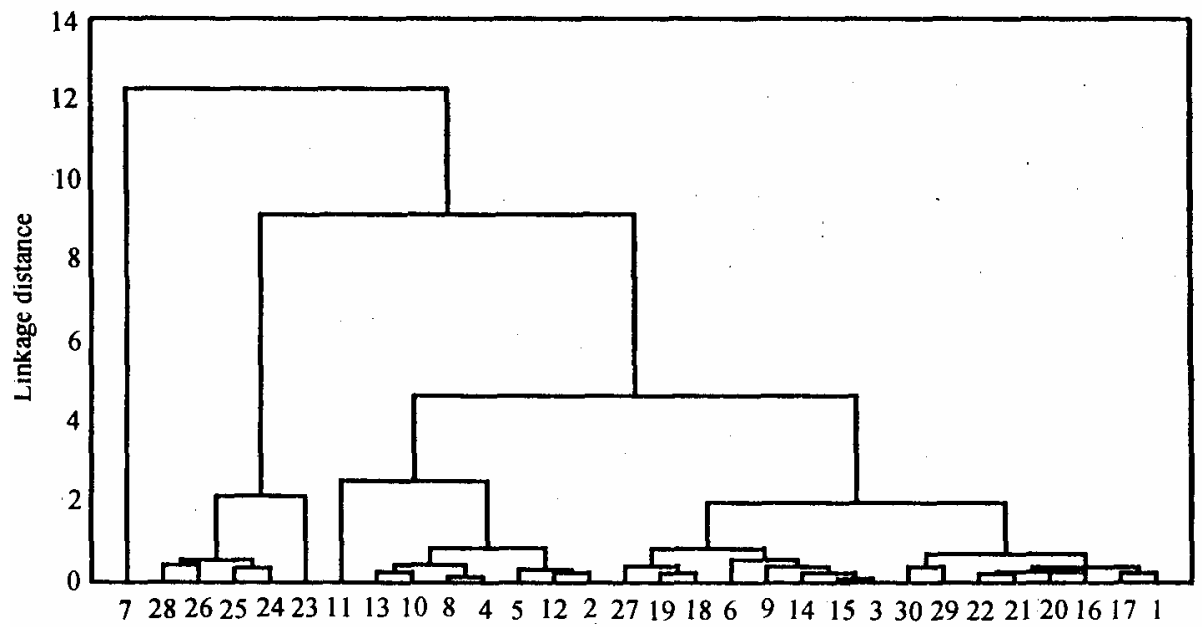

Figure Ib. Tree linkage diagram of Apis florea bee populations from Northern Vietnam (1-15) and Thailand (16-30). 
Contrary to A. cerana and A. florea, A. dorsata bees in Thailand are bigger in body size than those in Vietnam, but the differences of the measured characters and the tree diagram analysis (Figure 1-c) could not support any distinction at the species levels between these two bee populations.

Regarding the giant honey bees (A. dorsata), Maa (1953) created a genus Megapis with four species: Megapis breviligula, M. binghami, $M$. dorsata and $M$. laboriosa. On the other hand, Ruttner (1988) stated that there is very little evidence to support the idea of distinguishing $A$. dorsata into different subspecies, although its distribution is in a large range of the Southeast Asian region. However, according to his opinion, $A$. dorsata in this area can be separated only into two subspecies: $A$. $d$. breviligula and $A$. $d$. binghami. In this study, the differences in morphological characteristics of $A$. dorsata populations from Vietnam and Thailand are rather low to make any conclusion at the species level of classification.

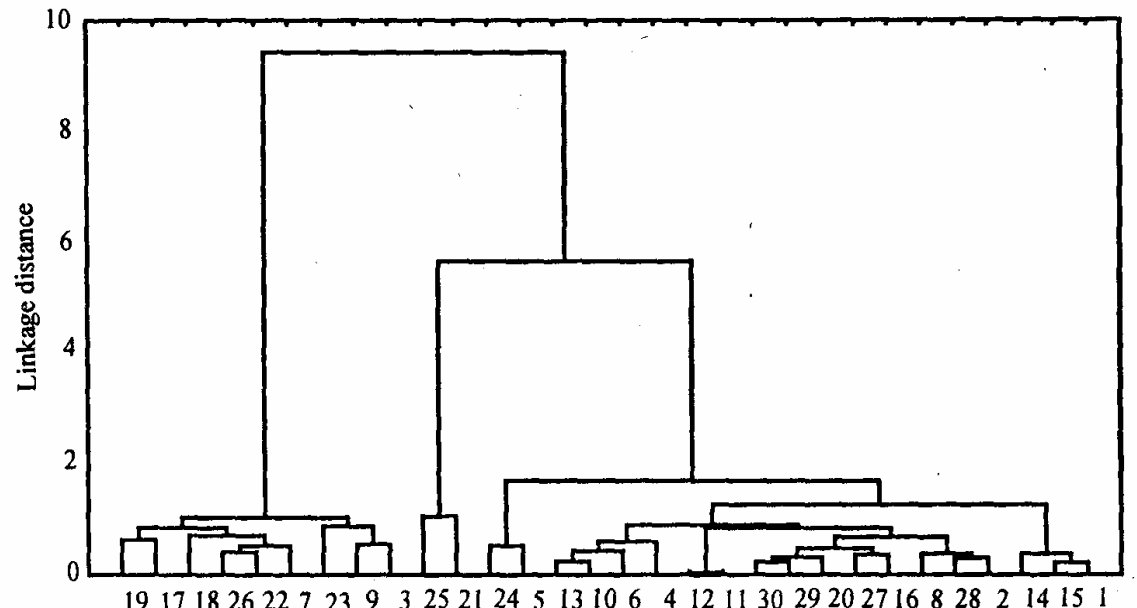

Figure Ic. Tree linkage diagram of Apis dorsata bee populations from Northern Vietnam (1-15) and Thailand (16-30).

\section{ACKNOWLEDGMENTS}

We would like to thank Prof. Dr. Siriwat Wongsiri, Mrs. Wandee Wattanachaiyngcharoen (Bee Biology Research Unit, Chulalongkorn University, Thailand) and Dr. Det Wattanachaiyangcharoen, Mr. Sawang Piyapichart (Faculty of Agriculture, Natural Resources and Environmental Science, Naresuan University, Thailand) for organizing a field trip to collect samples of A. dorsata. We are grateful to Prof. Nguyen Dinh Hien (Hanoi Agricultural University) for helping in statistical analysis. We thank Prof. T. Q. Hoc (Vietnam National University, Hanoi) for helpful suggestions on the manuscript and the correction. 
Morphological comparison of three Asian native honey bees - N.V. Niem \& L.Q. Trung

\section{REFERENCES}

Damus, M.S. and G.W. Otis. 1997. A morphological analysis of A. cerana F. and A. nigrocincta Smith populations from Southeast Asia. Apidologie 28:309 - 319.

Maa, Tsing-chao. 1953. An inquiry into the systematics of the tribe Apidini or honey bees (Hym.) Treubia21(3)525-640.

Peng, Y.S., M.E. Nasr and S.J. Loske. 1989. Geographical races of A. cerana Fabricius in China and their distribution. Review of recent Chinese publications and a preliminary statistical analysis.

Apidologie 20:9 -12.

Rinderer, I.E., B. P. Oldroyd, S. Wongsiri, H.A. Sylvester, L.l.de Guzman, J.A. Stelzer and R.M. Riggio. 1995. A morphological comparison of the dwarf honey bees of Southern Thailand and Palawan, Philippines. Apidologie 26:387-394.

Ruttner, F. 1988. Biogeography and Taxonomy of Honeybees. Springer-Verlag, Berlin.

Verma, L.R. 1990. Honey bee resources: Biology and management: 56 - 69. In Beekeeping in Integrated Mountain Development. Oxford \& IBH Publishing, New Delhi.

Wongsiri, S,, L. Chariya, P. Sureerat. 1993. Biological control of Varroa mite: Mass rearing biological control agent by crossing the Chinese strain Apis cerana with the Thai strain A. cerana indica by instrumental insemination. Asian Apiculture, p. 148 -155. 